\title{
Expression of p53, p21 (Waf1/Cip1/Sdi1) and Fas antigen in collagen vascular and granulomatous lung diseases
}

\author{
R. Kunitake, K. Kuwano, H. Miyazaki, M. Kawasaki, N. Hagimoto, M. Fujita, Y. Kaneko, N. Hara
}

Expression of p53, p21 (Wafl/Cip1/Sdi1) and Fas antigen in collagen vascular and granulomatous lung diseases. R. Kunitake, K. Kuwano, H. Miyazaki, M. Kawasaki, N. Hagimoto, M. Fujita, Y. Kaneko, N. Hara. CERS Journals Ltd 1998.

ABSTRACT: Fas is expressed in various cells and transduces the cell death signal. p21 is a mediator of p53-dependent $G_{1}$ arrest associated with deoxyribonucleic acid (DNA) damage. The upregulation of p53 and p21 associated with DNA damage in idiopathic pulmonary fibrosis has been described previously. In this study, p53, p21, and Fas expression and DNA damage were examined in interstitial pneumonia associated with collagen vascular diseases (CVD-IP).

DNA damage was assessed by terminal deoxynucleotidyl transferase-mediated deoxyuridine triphosphate biotin nick end-labelling (TUNEL) and p53, p21 and Fas proteins were detected by immunohistochemistry in 13 cases of CVD-IP, 13 of sarcoidosis, seven of hypersensitivity pneumonitis (HP) and eight control patients with normal lung parenchyma.

TUNEL-positive signals were found in bronchiolar or alveolar epithelial cells in 11 of $13(85 \%)$ specimens of CVD-IP, but not in sarcoidosis, HP or controls, except for a case of chronic HP with pulmonary fibrosis. p53, p21 and Fas were detected in bronchiolar or alveolar epithelial cells in nine $(69 \%), 10(77 \%)$ and $12(92 \%)$ of 13 specimens of CVD-IP, respectively, but not in sarcoidosis, HP or controls, except for a case of chronic HP.

These results suggest that the upregulation of p53, p21 and Fas in bronchiolar and alveolar epithelial cells associated with deoxyribonucleic acid damage may participate in the process of pulmonary fibrosis in interstitial pneumonia associated with collagen vascular diseases and chronic hypersensitivity pneumonitis.

Eur Respir J 1998; 12: 920-925.

The functions of wild-type p53 protein appear to include the inhibition of cell growth by the regulation of a $\mathrm{G}_{1} / \mathrm{S}$ cell cycle checkpoint and the mediation of apoptosis in certain situations in response to deoxyribonucleic acid (DNA) damage [1-4]. DNA strand breaks appear to be responsible for triggering increases in the $\mathrm{p} 53$ protein concentrations [4]. The wild-type p53 protein may normally act to suppress cell growth while the cell attempts DNA repair. It also may promote apoptosis in those cells that have irreparably damaged DNA, or which continue to proliferate.

A 21,000 Da protein, variously known as Cip1 (for Cdk-interacting protein) [5], Sdi1 (for senescent cell-derived inhibitor) [6] and Waf1 (for wild-type p53-activated fragment) [7], which inhibits cyclin-Cdk complex kinase activity [5], has been identified by three groups. p21 is induced in wild-type $\mathrm{p} 53$-containing cells following exposure to DNA-damaging agents, but not in mutant p53-containing cells [8]. Therefore, p21 is a critical downstream effector in the p53-specific pathway of growth control in mammalian cells [8].

Fas antigen is a cell-surface protein that mediates apoptosis. It is expressed in various cells and tissues including the thymus, liver, ovary, heart, and lung. It has structural homology with a number of cell-surface receptors, including tumour necrosis factor receptor and nerve growth fac-
Research Institute for Diseases of the Chest, Faculty of Medicine, Kyushu University, Fukuoka, Japan.

Correspondence: K. Kuwano

Research Institute for Diseases of the Chest

Faculty of Medicine

Kyushu University

3-1-1, Maidashi

Higashiku, Fukuoka 812-8582

Japan

Fax: 81926425389

Keywords: Collagen vascular disease Fas antigen

hypersensitivity pneumonitis

p21 (Waf1/Cip1/Sdi1)

p53

sarcoidosis

Received: March 261997

Accepted after revision July 51998 tor receptor [9]. Mice carrying the lymphoproliferative (lpr) mutation have defects in the Fas antigen gene [10]. The lpr mice develop lymphadenopathy and suffer from a systemic lupus erythematosus-like autoimmune disease, indicating an important role for Fas in the negative selection of autoreactive T-cells in the thymus [10].

It has been previously demonstrated that p53 and p21 are upregulated in the lungs of patients with idiopathic pulmonary fibrosis (IPF). p53 and p21 were localized predominantly in the epithelial cells of the terminal airways and alveoli [11]. It has been demonstrated that Fas is expressed in bronchiolar and alveolar epithelial cells in normal lung tissues [12] and it has also been found that Fas is upregulated in bronchiolar and alveolar epithelial cells in IPF [13]. Alveolitis is probably the earliest detectable manifestation of lung injury in pulmonary fibrosis [14] and loss of normal epithelial cells after irreparable damage may lead to pulmonary fibrosis. It was hypothesized that DNA strand breaks and upregulation of p53, p21 and Fas expression in alveolar epithelial cells may associate with interstitial pneumonia associated with collagen vascular diseases (CVD-IP), as in IPF. The expression of these proteins and DNA strand breaks was also investigated in bronchiolar and alveolar epithelial cells in granulomatous lung diseases which do not usually progress to pulmonary fibrosis. 


\section{Materials and methods}

\section{Case materials}

The study of CVD-IP was performed on lung tissues obtained by transbronchial lung biopsy (TBLB) from 13 patients (five males and eight females, mean age $56 \mathrm{yrs}$, range 37-63 yrs). Four patients were smokers and nine were nonsmokers. There were eight cases of rheumatoid arthritis, two cases of dermatomyositis with polymyositis, two cases of progressive systemic sclerosis, and one case of mixed connective tissue disease. The diagnosis of collagen vascular diseases was based on clinical criteria using a combination of medical history, physical examination, laboratory tests, and chest radiography. Chest radiography showed a pattern suggesting interstitial involvement in all 13 cases and chest computed tomography (CT) exhibited the usual features of fibrosing alveolitis, including ground-glass attenuation, irregular thickening of bronchovascular bundles, and honeycombing. Patients with collagen vascular diseases were all in the chronic stage and pathological findings of lung biopsy specimens were consistent with those of fibrosing alveolitis. More than three specimens from different parts of the lung were obtained by TBLB. The specimens included bronchiolar and alveolar epithelial cells.

The results from those patients with CVD-IP were compared with those in eight specimens from normal lung parenchyma obtained by lobectomy for a solitary pulmonary nodule, 13 lung specimens from patients with sarcoidosis, and seven specimens from patients with hypersensitivity pneumonitis (HP) obtained by TBLB, except for a specimen obtained by open lung biopsy from a patient with chronic HP accompanied by pulmonary fibrosis. The patients with a solitary pulmonary nodule consisted of three males and five females, four out of eight of whom were smokers, aged 56-78 yrs (mean 67 yrs). The patients with sarcoidosis consisted of five males and eight females, six out of 13 of whom were, aged 25-68 yrs (mean 41 yrs). The patients with HP consisted of two males and five females, two out of seven of whom were smokers, aged 55-71 yrs (mean $60 \mathrm{yrs}$ ). The diagnosis of sarcoidosis and HP was based on clinical criteria using a combination of medical history, physical examination, laboratory tests, and chest radiography and confirmed by pathological findings with the presence of noncaseous epithelioid granulomas in tissue samples.

\section{Tissue preparation}

The tissue samples were fixed in $10 \%$ formalin overnight and embedded in paraffin. Two 5- $\mu$ m paraffin sections were adhered to slides pretreated with poly-L-lysine. Deparaffinization was accomplished by heating the sections for $2 \mathrm{~h}$ at $70^{\circ} \mathrm{C}$. These sections were dewaxed by washing three times for 5 min each in xylene, then rehydrated in $100 \%, 95 \%$, and $80 \%$ ethanol for 5 min each, and finally rinsed with distilled water.

\section{DNA nick end-labelling of tissue sections}

The method of terminal deoxynucleotidyl transferase (TDT) mediated deoxyuridinetriphosphate (dUTP) biotin nick end-labelling (TUNEL) was performed according to the protocols described previously [15] with slight modifications [11]. The nuclei of tissue sections were stripped of proteins by incubation with $20 \mu \mathrm{g} \cdot \mathrm{mL}^{-1}$ of proteinase $\mathrm{K}$ for $10 \mathrm{~min}$ and washed with $0.5 \%$ Triton-X100 in phosphatebuffered saline (PBS) for $5 \mathrm{~min}$. The slides then were incubated in $1 \%$ glycine-PBS solution. After being rinsed with distilled water, the slides were immersed in TDT buffer (30 mM Tris at $\mathrm{pH} 7.2,140 \mathrm{mM}$ sodium cacodylate, 1 $\mathrm{mM}$ cobalt chloride). TDT $\left(0.3 \mathrm{U} \cdot \mu \mathrm{L}^{-1}\right)$ and biotin-16dUTP (Boehringer Mannheim, Mannheim, Germany) in TDT buffer were then added to cover the sections and incubated with streptavidin-alkaline phosphatase conjugate (Bethesda Research Laboratories, Gaithersburg, MD, USA) at a concentration of $1 \mathrm{U} \cdot \mathrm{mL}^{-1}$ for $30 \mathrm{~min}$ at $37^{\circ} \mathrm{C}$. After being rinsed with distilled water, the slides were washed three times for 5 min each in $0.5 \%$ Triton-X100/ PBS, followed by three 5-min washes in PBS and three 5-min washes in AP 9.6 (0.1 M Tris- $\mathrm{HCl}$ at $\mathrm{pH} 9.6,0.1 \mathrm{M}$ $\mathrm{MgCl}_{2}$ ). They were then immersed in AP 9.6 containing 5-bromo-4-chloro-3-indole phosphate, $169 \mu \mathrm{g} \cdot \mathrm{mL}^{-1}$ (Sigma Chemical Co., St Louis, MO, USA) and nitroblue tetrazolium, $331 \mu \mathrm{g} \cdot \mathrm{mL}^{-1}$ (Sigma) and left in the dark for $30 \mathrm{~min}$. The colour reaction was stopped by washing with disodium ethylenediaminotetraacetic acid (EDTA) and the slides were examined under a light microscope. For positive controls, sections of the intestine of guinea-pigs were stained concurrently with other sections. For negative controls, TDT was omitted from the reaction mixture.

\section{Immunohistochemistry for p53, p21 and Fas}

Hydrated autoclaving was used as a pretreatment to immunostaining as described previously [16]. Following deparaffinization in xylene and rehydration through ethanol to water, the tissue sections were autoclaved at $121^{\circ} \mathrm{C}$ for $20 \mathrm{~min}$ in a stainless-steel pot filled with enough distilled water to immerse the sections completely (hydrated autoclaving). The monoclonal mouse anti-human p53 protein (DO-1) (Oncogene Science, Cambridge, MA, USA), the monoclonal mouse anti-human p21 WAFI protein (WAF-1) (Oncogene Science) and monoclonal mouse anti-human Fas antibody (UB2) (MBL, Nagoya, Japan) were used. Immunohistochemistry was performed using a modified streptavidin-biotinylated peroxidase technique with a Histofine SAB-PO kit (Nichirei Corporation, Tokyo, Japan). Nonspecific protein staining was blocked by rabbit serum for $30 \mathrm{~min}$ at room temperature. The sections were incubated with specific antibody at $4^{\circ} \mathrm{C}$ overnight. The sections were rinsed with PBS and incubated with biotinylated anti-mouse immunoglobulin for $30 \mathrm{~min}$, washed and treated with $0.3 \%$ hydrogen peroxide in methanol for 30 min to inhibit the activity of any endogenous peroxidases. The slides were washed, incubated with streptavidinperoxidase complex for $30 \mathrm{~min}$ and developed according to the manufacturer's directions. For control incubations, specific antibody was replaced with normal mouse immunoglobulin $\mathrm{G}$ (IgG). For double immunostaining, immunohistochemistry for Fas was performed first as mentioned above, followed by p53 or p21 detection using a streptavidin-alkaline phosphatase-substrate system (Vector Laboratories, Burlingame, CA, USA). 


\section{Results}

\section{Histological findings}

Lung sections from patients with CVD-IP showed thickened alveolar interstitium and alveolar type II cell hyperplasia with mild infiltration of mononuclear cells (fig. 1A). Lung sections obtained from patients with a solitary pulmonary nodule for controls showed normal lung parenchyma. Lung sections from patients with sarcoidosis and HP, except for a case of chronic HP, showed epithelioid granulomas, infiltration of inflammatory cells and no features of fibrosis. A lung section of a case of chronic HP showed the foci of granulomatous components and mild to moderate fibrosis in the thickened alveolar septa with infiltration of mononuclear cells (fig. 2A).

\section{DNA nick end-labelling}

The frequency of TUNEL-positive cells was graded from 0 to 3 according to the percentage of nuclei stained: graded as 0 , none; $1,<10 \% ; 2,10-20 \%$; and $3,>20 \%$. The TUNEL results are summarized in tables 1 and 2. Positive signals for TUNEL were detected in 11 of $13(85 \%)$ lung specimens from patients with CVD-IP. In CVD-IP, prominent intranuclear staining with the TUNEL method was seen in bronchiolar and alveolar epithelial cells (fig. 1B). In contrast, positive staining was not seen in any of the specimens from eight patients with a solitary pulmonary nodule, 13 patients with sarcoidosis or any of the specimens from patients with HP, except for a case of chronic HP. The case of chronic HP showed positive signals in bronchiolar and alveolar epithelial cells (fig. 2B).

\section{Immunohistochemistry}

For the immunohistochemistry, the frequency of p53, p21 and Fas expression was graded from 0 to 3 according to the percentage of nuclei stained: graded as 0 , none; 1 , $<10 \% ; 2,10-50 \%$; and 3, $>50 \%$ of the nuclei. A summary of immunohistochemistry data are shown in tables 1 and 2. With immunohistochemistry for p53, nine of $13(69 \%)$ patients with CVD-IP were positive. The most prominent signal was seen in hyperplastic epithelial cells (fig. 1C). With immunohistochemistry for p21, 10 of 13 (77\%) patients with CVD-IP gave positive signals in the bronchiolar or alveolar epithelial cells (fig. 1D). With immunohistochemistry for Fas, lung specimens from 12 of $13(92 \%)$ patients with CVD-IP gave positive signals in the bronchiolar or alveolar epithelium (fig. 1E). Conversely, none of the bronchiolar or alveolar epithelial cells in eight normal lung parenchyma, 13 patients with sarcoidosis, or six patients with HP gave positive signals for p53, p21 and Fas. A patient with chronic HP accompanied with pulmonary fibrosis demonstrated positive signals for p53, p21 and Fas in bronchiolar and alveolar epithelial cells (fig. 2C-E,
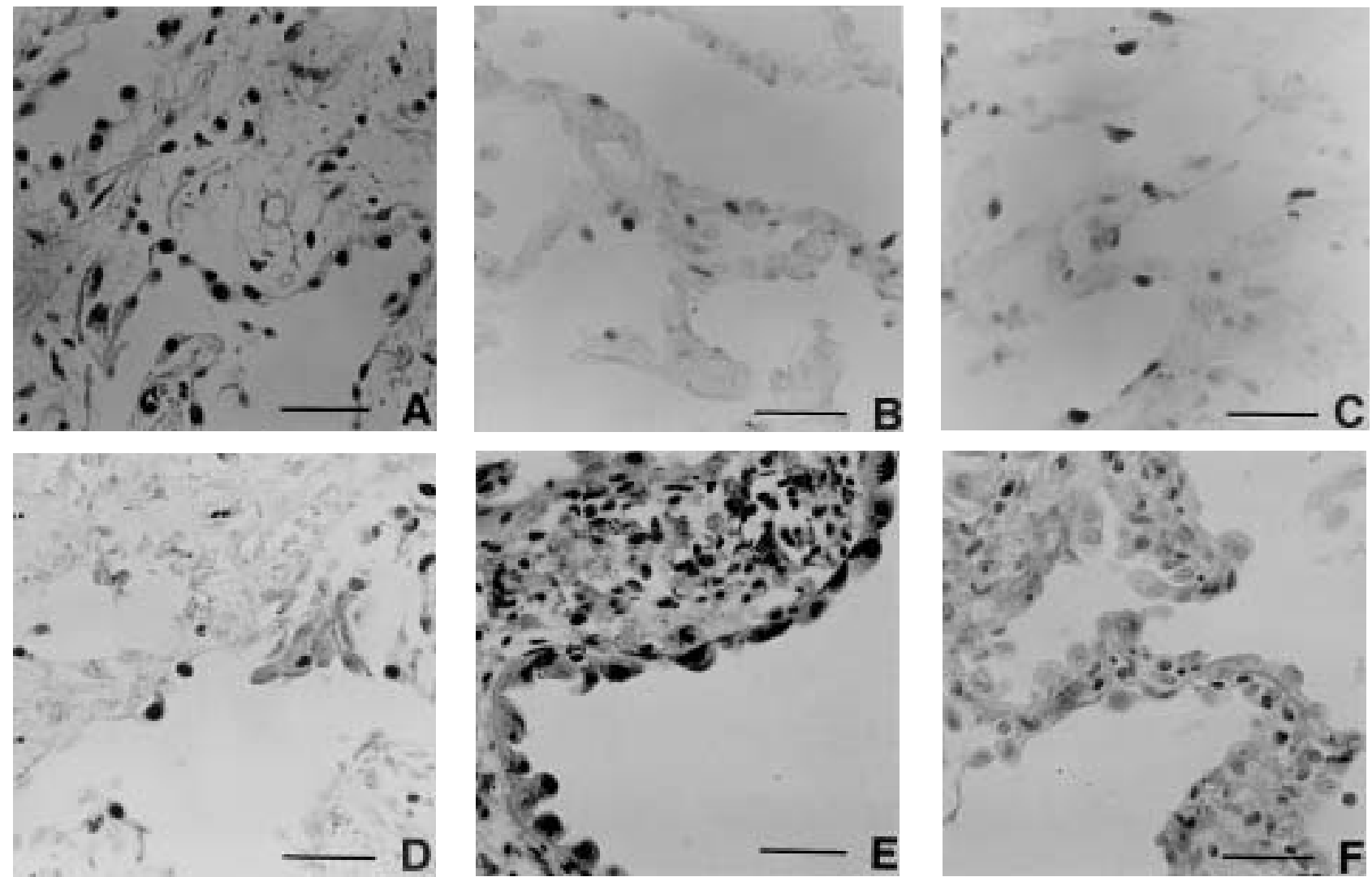

Fig. 1. - Terminal deoxynucleotidyl transferase-mediated deoxyuridine triphosphate biotin nick end-labelling (TUNEL) and immunohistochemistry for p53, p21 and Fas in interstitial pneumonia associated with collagen vascular diseases (CVD-IP). A) Lung sections of CVD-IP, stained with haematoxylin and eosin, showing thickened alveolar walls with mild infiltration of mononuclear cells. B) TUNEL reveals the localization of deoxyribonucleic acid (DNA) strand breaks in alveolar epithelial cells. Positive signals for C) p53 and D) p21 protein are detected in alveolar epithelial cells. E) Positive signals for Fas seen in alveolar epithelial cells. F) Control sections stained with nonimmune mouse immunoglobulin G showing no positive signal. (Internal scale bars $=50 \mu \mathrm{m}$.) 

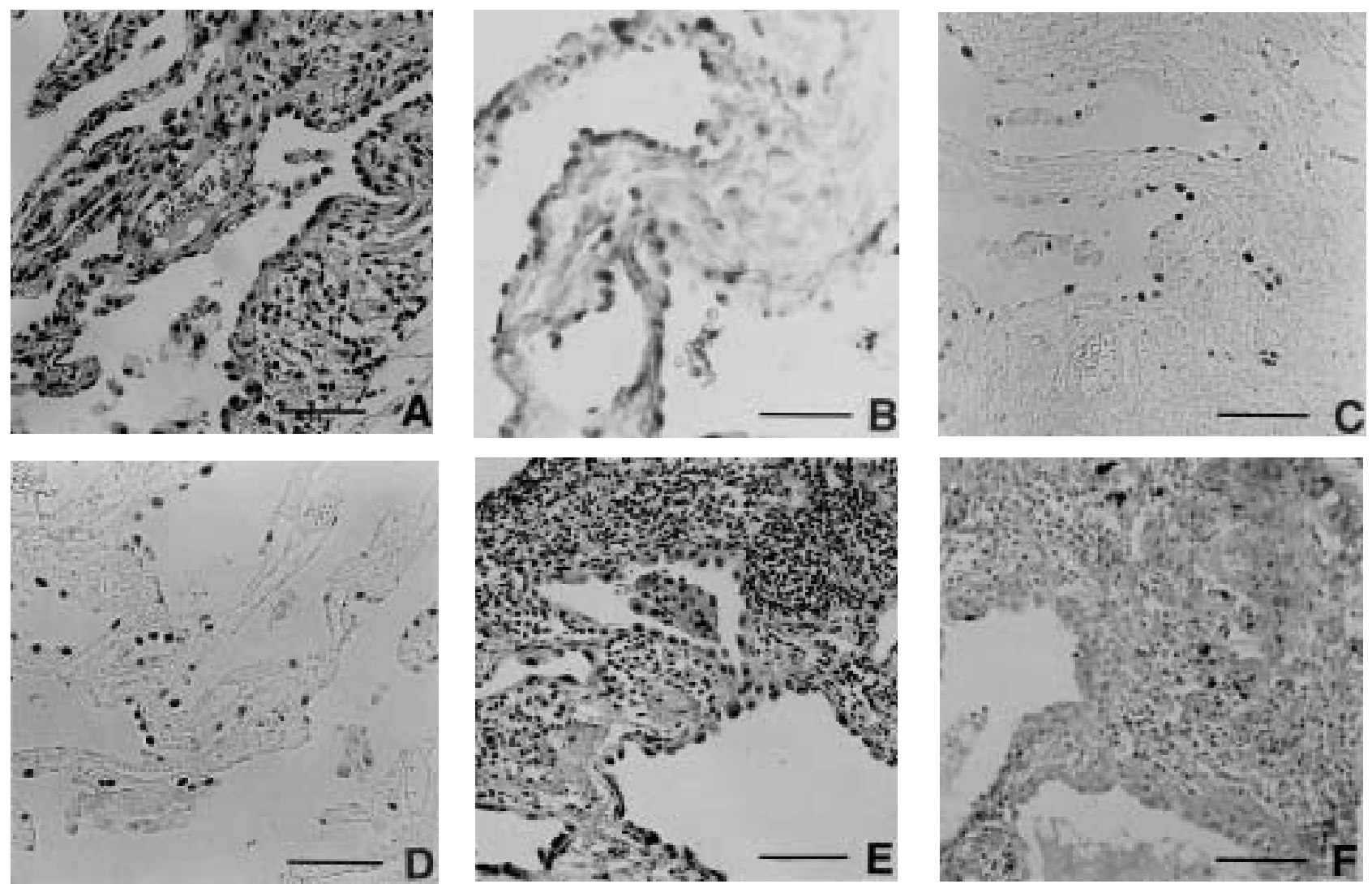

Fig. 2. - Terminal deoxynucleotidyl transferase-mediated deoxyuridine triphosphate biotin nick end-labelling (TUNEL) and immunohistochemistry for p53, p21 and Fas in chronic hypersensitivity pneumonitis (HP). A) Lung sections of chronic HP, stained with haematoxylin and eosin, showing mild-to-moderate fibrosis with infiltration of mononuclear cells. B) TUNEL reveals the localization of deoxyribonucleic acid (DNA) strand breaks in alveolar epithelial cells. The most prominent signals for C) p53 and D) p21 protein are detected in cystic areas lined with bronchiolar or alveolar epithelial cells. E) Positive signals for Fas seen in bronchiolar or alveolar epithelial cells. F) Control sections stained with nonimmune mouse immunoglobulin $\mathrm{G}$ showing no positive signal. (Internal scale bar $=100 \mu \mathrm{m}$.)

respectively). Both p53 and p21 were distributed in the same types of cells; mainly in hyperplastic epithelial cells of terminal airways and alveoli. For negative controls, sections stained with nonimmune mouse IgG showed no positive signal (figs. $1 \mathrm{~F}$ and $2 \mathrm{~F}$ ).

Paired immunohistochemistry for Fas with p53 or p21 was also performed in CVD-IP cases. Positive reactions for Fas were found in the cytoplasm, whereas p53 (fig. 3A) and p21 (fig. 3B) were detected in the nucleus in hyperplastic epithelial cells. Occasional epithelial cells showed positive signals for Fas in the absence of those for p53 or p21 and only a few epithelia showed positive signals for p53 or p21 in the absence of those for Fas.

\section{Discussion}

DNA strand breaks and upregulation of p53, p21 and Fas have been demonstrated in hyperplastic type II pneumocytes and bronchiolar epithelial cells in CVD-IP. In lung tissues of chronic HP accompanied with pulmonary fibrosis, as well as in CVD-IP and IPF [11], both these proteins and DNA strand breaks were detected. Upregulation of these proteins, associated with DNA strand breaks, in bronchiolar and alveolar epithelial cells may not be specific for IPF, but observed in any fibrosing lung disease. These phenomena are not found in granulomatous lung diseases without fibrosis.
In CVD-IP, as in IPF, there is patchy interstitial inflammation, fibrosis and altered alveolar architecture with regeneration and remodelling, which results in the formation of honeycomb cysts once the disease has progressed to an advanced stage. It is felt that the initial lesion prior to the formation of fibrosis is probably an alveolitis, which is characterized by the loss of type I epithelial cells and type II pneumocyte hyperplasia. The proliferation of type II pneumocytes and the formation of honeycomb cysts are regenerative phenomena of the lung that occur following intense pulmonary injury and inflammation [14].

The role of p53 and p21 as key elements in the cascade of events initiated by DNA damage and other forms of cellular injury has been elucidated mainly from experiments on cells and in culture. In response to DNA damage, the level of p53 protein increases and acts as a checkpoint control by blocking the cell cycle in the $G_{1}$ phase, which results either in a delay in progress through the cell cycle to allow repair processes, or in the initiation of programmed cell death $[1,2]$. The induction of $\mathrm{p} 21$ expression in wild-type p53-containing cells but not in mutant p53containing cells by exposure to DNA-damaging agents supports the notion that $\mathrm{p} 21$ may be a critical effector of p53-mediated cell cycle control [8].

Although many experiments indicate that $\mathrm{p} 53$ regulates the cell cycle and DNA repair, only recently has an experimental result supported a role for p53 in wound repair in vivo. ANTONIADES et al. [17] demonstrated p53 expression in 
Table 1. - Results of terminal deoxynucleotidyl transferase-mediated deoxyuridine triphosphate biotin nick end-labelling (TUNEL) and immunohistochemistry for p53, p21 and Fas in bronchiolar and alveolar epithelial cells in interstitial pneumonia associated with collagen vascular diseases

\begin{tabular}{lcclllll}
\hline $\begin{array}{l}\text { Patient } \\
\text { No. }\end{array}$ & $\begin{array}{c}\text { Age } \\
\text { yrs }\end{array}$ & Sex & $\begin{array}{c}\text { Associated } \\
\text { disease }\end{array}$ & TUNEL & Fas & p53 & p21 \\
\hline 1 & 39 & M & PSS & 2 & 2 & 2 & 2 \\
2 & 38 & F & DM & 2 & 2 & 3 & 3 \\
3 & 64 & F & RA & 3 & 2 & 2 & 2 \\
4 & 60 & F & PSS & 2 & 2 & 2 & 3 \\
5 & 56 & F & RA & 1 & 2 & 2 & 2 \\
6 & 50 & M & PM & 2 & 2 & 2 & 2 \\
7 & 59 & M & RA & 0 & 1 & 0 & 0 \\
8 & 59 & F & RA & 2 & 2 & 2 & 2 \\
9 & 51 & F & RA & 2 & 1 & 0 & 0 \\
10 & 58 & F & MCTD & 0 & 0 & 0 & 0 \\
11 & 50 & M & RA & 1 & 2 & 0 & 1 \\
12 & 65 & M & RA & 2 & 3 & 2 & 2 \\
13 & 54 & F & RA & 2 & 2 & 1 & 2 \\
\hline
\end{tabular}

The frequency of TUNEL-positive cells was graded from 0 to 3 according to the percentage of nuclei stained: 0 , none; 1 , $<10 \% ; 2,10-20 \% ; 3,>20 \%$. The frequency of immunohistochemistry was graded from 0 to 3 according to the percentage of cells stained: 0 , none; $1,<10 \% ; 2,10-50 \% ; 3,>50 \%$. M: male; F: female; PSS: progressive systemic sclerosis; DM: dermatomyositis; RA: rheumatoid arthritis; PM: polymyositis; MCTD: mixed connective tissue disease.

response to acute cutaneous injury in swine. They suggested the presence of a well-controlled physiological mechanism including p53 that regulates in vivo the processes of normal tissue repair in response to injury. DiDENKO et al. [18] demonstrated that expression of p53 and p21 was induced by ischaemia/reperfusion injury in the adrenal cortex. GuineE et al. [19] demonstrated that increased p53 and p21 expression in diffuse alveolar damage reflects normal physiological upregulation in response to cellular and DNA damage and is associated with apoptosis of type II pneumocytes.

Whether the p53 protein is wild-type or mutant cannot be determined by immunohistochemistry. However, we believe that some of the induced p53 protein is wild-type p53, because p21 is induced by wild-type but not mutant p53 [8] and both were expressed in the same type of cells. In this way, p53 and p21 play important roles in the inhibition of cellular proliferation and promote the repair of tissue injury in CVD-IP lung tissues as well as IPF.

The expression of Fas was detected in hyperplastic bronchiolar and alveolar epithelial cells in CVD-IP. In contrast to CVD-IP, Fas was not or only very weakly ex-

Table 2. - Positivity for terminal deoxynucleotidyl transferase-mediated deoxyuridine triphosphate biotin nick end-labelling (TUNEL) and immunohistochemistry for p53, p21 and Fas in bronchiolar and alveolar epithelial cells

\begin{tabular}{lcccccccr}
\hline Disease & \multicolumn{2}{c}{ TUNEL } & \multicolumn{2}{c}{ Fas } & \multicolumn{2}{c}{ p53 } & \multicolumn{2}{c}{ p21 } \\
\hline CVD-IP & $11 / 13$ & $(85)$ & $12 / 13$ & $(92)$ & $9 / 13$ & $(69)$ & $10 / 13$ & $(77)$ \\
Sarcoidosis & $0 / 13$ & $(0)$ & $0 / 13$ & $(0)$ & $0 / 13$ & $(0)$ & $0 / 13$ & $(0)$ \\
HP & $1 / 7$ & $(14)$ & $1 / 7$ & $(14)$ & $1 / 7$ & $(14)$ & $1 / 7$ & $(14)$ \\
Control & $0 / 8$ & $(0)$ & $0 / 8$ & $(0)$ & $0 / 8$ & $(0)$ & $0 / 8$ & $(0)$
\end{tabular}

Data are presented as number with percentages in parentheses. CVD-IP: interstitial pneumonia associated with collagen vascular diseases; HP: hypersensitivity pneumonitis.

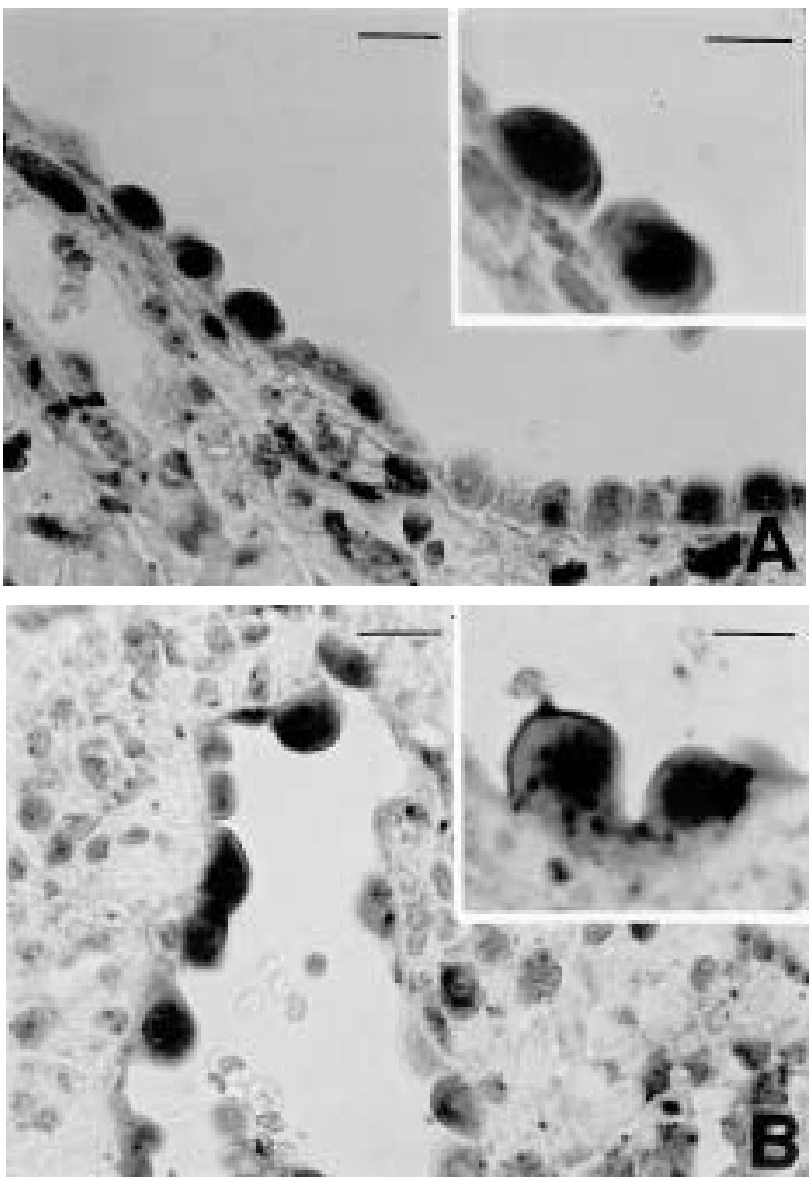

Fig. 3. - Double immunostaining for Fas with p53 and with p21. A) Colocalization of positive signals for Fas in cytoplasm and for p53 in nucleus in hyperplastic alveolar epithelial cells. There was a lack of p53 staining in the other Fas-positive cells. B) Colocalization of positive signals for Fas in cytoplasm and for p21 in the nucleus in hyperplastic alveolar epithelial cells. There was also a lack of p21 staining in the other Fas-positive cells. (Internal scale bar A, B=50 $\mu \mathrm{m}$; insets=25 $\mu \mathrm{m}$.)

pressed in bronchiolar and alveolar epithelial cells in granulomatous lung diseases without fibrosis. These results indicate that Fas is an inducible molecule that can be expressed in bronchiolar and alveolar epithelial cells in the lung tissues from patients with fibrosing lung diseases and that Fas-mediated apoptosis may be associated with the loss of lung parenchyma and the progression of fibrosis.

Sequence analysis of the human Fas has revealed the presence of a p53CON element approximately 1.3 kilobase upstream in the 5'-flanking region of the gene [20, $21]$ and the induction of Fas expression by exogenous wild-type p53 has been demonstrated [22]. Furthermore, anti-Fas antibody crosslinking induces Fas-mediated apoptosis through upregulation of p53 and p21 in p53-transfected cancer cells [23, 24]. MüLler et al. [25] demonstrated that drug-induced apoptosis in cells mediated by the Fas/ Fas ligand system involved the activation of wild-type p53. These results suggested that there was an amplifying signal loop for apoptosis between p53 and Fas. These cell cycle regulatory proteins and Fas may be linked to each other and regulate the cell proliferation and death of bronchiolar and alveolar epithelial cells in fibrosing lung diseases.

Hepatocytes with Fas in hepatitis C virus-infected liver were found particularly among the infiltrating lymphocytes 
[26]. The hepatocytes that show early changes of apoptosis have also been found to have lymphocytes closely ajoining to their surfaces [27] and these lymphocytes were revealed to be mainly composed of cytotoxic T-lymphocytes (CTL) [28, 29]. Some reports have shown that the death of CTL targets is apoptotic during viral infections, autoimmune reactions, and graft rejection [30]. CTLs probably interact with the target cell by way of specific target cell membrane proteins. Fas may be one of these proteins and the binding of a CTL to Fas might induce the cell to undergo apoptosis. This mechanism may occur in lung tissues with CVD-IP as well as IPF, because bronchiolar and alveolar epithelial cells with positive signals for Fas and TUNEL were found in the fibrosing region, where the lymphocytes infiltration was usually seen.

In conclusion, deoxyribonucleic acid strand breaks and the upregulation of p53, p21 and Fas expression in bronchiolar and alveolar epithelial cells were found in interstitial pneumonia associated with collagen vascular diseases but not in these cells in granulomatous lung diseases not accompanied by pulmonary fibrosis. These factors may be expressed not only to allow time to repair the damage but also to promote tissue damage, especially when expression is excessive and chronic, as in idiopathic pulmonary fibrosis. By associating with each other, the upregulation of these proteins in bronchiolar and alveolar epithelial cells could render them susceptible to apoptosis and may be involved in the loss of normal lung parenchyma in the fibrosing process.

\section{References}

1. Kastan MB, Onyekwere O, Sidransky D, Vogelstein B, Craig RW. Participation of $\mathrm{p} 53$ protein in the cellular response to DNA damage. Cancer Res 1991; 51: 6304-6311.

2. Kuerbitz SJ, Plunkett BS, Walsh WV, Kastan MB. Wildtype p53 is a cell cycle checkpoint determinant following irradiation. Proc Natl Acad Sci USA 1992; 89: 7491-7495.

3. Lowe SW, Schmitt EM, Smith SW, Osborne BA, Jacks T. p53 is required for radiation-induced apoptosis in mouse thymocytes. Nature 1993; 362: 847-849.

4. Nelson WG, Kastan MB. DNA strand breaks: the DNA template alterations that trigger p53-dependent DNA damage response pathways. Mol Cell Biol 1994; 14: 18151823.

5. Harper JW, Adami GR, Wei N, Keyomarsi K, Elledge SJ. The p21 Cdk-interacting protein Cip1 is a potent inhibitor of G1 cyclin-dependent kinases. Cell 1993; 75: 805-816.

6. Noda A, Ning Y, Venable SF, Pereira-Smith OM, Smith JR. Cloning of senescent cell-derived inhibitors of DNA synthesis using an expression screen. Exp Cell Res 1994; 211: 90-98.

7. El-Deily WS, Takashi T, Veluculescu VE, et al. WAF1, a potential mediator of p53 tumor suppression. Cell 1993; 75: 817-825.

8. El-Deiry WS, Harper JW, O'Connor PM, et al. WAF1/ CIP1 is induced in p53-mediated G1 arrest and apoptosis. Cancer Res 1994; 54: 1169-1174.

9. Itoh N, Yonehara S, Ishii SA, et al. The polypeptide encoded by the cDNA for human cell surface antigen Fas can mediate apoptosis. Cell 1991; 66: 233-243.

10. Watanabe-Fukunaga R, Brannan CI, Copeland NG, Jenkins NA, Nagata S. Lymphoproliferation disorder in mice explained by defects in Fas antigen that mediates apoptosis. Nature 1992; 356: 314-317.

11. Kuwano K, Kunitake R, Kawasaki M, et al. p21 (Waf1/
Cip1) and p53 expression in association with DNA strand breaks in idiopathic pulmonary fibrosis. Am J Respir Crit Care Med 1996; 154: 477-483.

12. Leithäuser F, Dhein J, Mechtersheimer G, et al. Constitutive and induced expression of APO-1, a new member of the nerve growth factor/tumor necrosis factor receptor superfamily, in normal and neoplastic cells. Lab Invest 1993; 69: 415-429.

13. Kuwano K, Miyazaki H, Hagimoto N, et al. The involvement of Fas-Fas ligand pathway in fibrosing lung diseases. Am J Respir Cell Mol Biol 1998; in press.

14. Crystal RG, Bitterman PB, Rennard SI, Hance AJ, Keogh BA. Interstitial lung diseases of unknown cause: disorders characterized by chronic inflammation of the lower respiratory tract (first of two parts). N Engl J Med 1984; 310: 154-166.

15. Gavrieli Y, Sherman Y, Ben-Sasson SA. Identification of programmed cell death in situ via specific labeling of nuclear DNA fragmentation. J Cell Biol 1992; 119: 493-501.

16. Shin RW, Iwaki T, Kitamoto T, Tatelshi J. Hydrated autoclave pretreatment enhances tau immunoreactivity in formalin-fixed normal and Alzheimer's disease brain tissues. Lab Invest 1991; 64: 693-702.

17. Antoniades HN, Galanopoulos T, Neville-Golden J, Kiritsy CP, Lynch SE. p53 expression during normal tissue regeneration in response to acute cutaneous injury in swine. J Clin Invest 1994; 93: 2206-2214.

18. Didenko VV, Wane, X, Yang L, Hornsby PJ. Expression of p21 $1^{\mathrm{WAF} 1 / \mathrm{CIPI} / \mathrm{SDI} I}$ and p53 in apoptotic cells in the adrenal cortex and induction by ischemia/reperfusion injury. $J$ Clin Invest 1996; 97: 1723-1731.

19. Guinee D Jr, Fleming M, Hayashi T, et al. Association of p53 and WAF1 expression with apoptosis in diffuse alveolar damage. Am J Pathol 1996; 149: 531-538.

20. Behrmann I, Walczak H, Krammer PH. Structure of the human APO-1 gene. Eur J Immunol 1994; 24: 3057-3062.

21. Chen J, Liu C, Koopman WJ, Mountz JD. Characterization of human Fas gene: exon/intron organization and promoter region. J Immunol 1995; 154: 1239-1245.

22. Owen-Schaub LB, Zliang W, Cusack JC, et al. Wild-type human p53 and a temperature-sensitive mutant induce Fas/Apo-1 expression. Mol Cell Biol 1995; 15: 3032-3040.

23. Tamura T, Aoyama N, Saya H, et al. Induction of Fasmediated apoptosis in p53-transfected human colon carcinoma cells. Oncogene 1995; 11: 1939-1946.

24. Takahashi R. Role of p53 tumor suppressor gene and Fas/ APO-1 in induction of apoptosis and differentiation of cancer cells. Leukemia 1997; 3: 331-333.

25. Müller M, Strand S, Hug H, et al. Drug-induced apoptosis in hepatoma cells is mediated by the CD95 (APO-1/ Fas) receptor/ligand system and involves activation of wild-type p53. J Clin Invest 1997; 99: 403-413.

26. Hiramatsu N, Hayashi N, Katayama K, et al. Immunohistochemical detection of Fas antigen in liver tissue of patients with chronic hepatitis C. Hepatology 1994; 19: 1354-1359.

27. Kerr JFR, Cooksley WGE, Searle J, et al. The nature of piecemeal necrosis in chronic active hepatitis. Lancet 1979; 2: 827-828.

28. Russell JH. Internal disintegration model of cytotoxic lymphocyte-induced target damage. Immunol Rev 1983; 72: 97-118.

29. Takehara T, Hayashi N, Katayama K, et al. Two-dimensional flow cytometric analysis of intrahepatic lymphocytes subsets from patients with chronic hepatitis. Dig Dis Sci 1991; 36: 87-91.

30. Wyllie AH, Karr JFR, Currie AR. Cell death: the significance of apoptosis. Int Rev Cytol 1980; 8: 251-306. 